\title{
Frieden hat seinen Preis
}

\section{Jürg Kesselring}

Prof. Dr. med., Mitglied IKRK, Senior Botschafter und Neuroexperte, Rehabilitationszentrum Kliniken Valens

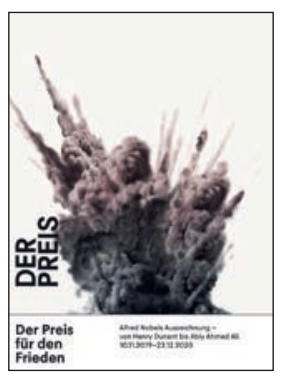

Kabinettausstellung Der Preis für den Frieden Alfred Nobels Auszeichnung - von Henry Dunant bis Abiy Ahmed Ali 10.11.2019-23.12.2020 Henry-Dunant-Museum, Heiden
Die letzten Jahre seines wechselvollen Lebens verbrachte Henry Dunant (1828-1910), der Gründer der Rotkreuz-Bewegung im Spital Heiden, als «Pensionär», wie er selber betonte, nicht als Patient. Sein Geburtstag, der 8. Mai, ist weltweit der «Rotkreuz-Tag». Die Idee zu diesem Gedenk-und-Feier-Tag entstand im Zusammenhang mit innenpolitischen Konflikten in der damaligen Tschechoslowakischen Republik 1921, als die dortige Rotkreuz-Gesellschaft, die heuer ihr 100-jähriges Bestehen gefeiert hat, vorschlug, die mittelalterliche Praxis des "Treuga dei» (Gottesfrieden) umzusetzen und an Ostern des Jahres 1922 eine dreitägige Waffenruhe ausrief, eine "Trêve de la Croix-Rouge» (Rotkreuz-Frieden). Statt polemischer Äusserungen veröffentlichte die Presse zu jener Zeit vermehrt Berichte über den Rotkreuz-Frieden. Daraus entstand der Wunsch, jedes Jahr einen Tag des Friedens zu begehen, was ab 1930 an den Internationalen Konferenzen der Rotkreuz-Gesellschaften diskutiert und erst auf der XVI. Internationalen Konferenz 1938 in London beschlossen wurde. Henry Dunant hat 1901 als Erster den Friedensnobelpreis erhalten und wurde dadurch nach jahrzehntelanger gesellschaftlicher Ächtung rehabilitiert. Das IKRK erhielt diesen Preis 1917 nach den Erfahrungen des Ersten Weltkrieges (der in Frankreich immer noch «La Grande Guerre» genannt wird), wo es für die 7 Millionen (!) Kriegsgefangenen in aufwendiger und komplizierter Kleinarbeit und grosszügiger Strategieplanung seine guten Dienste anbot und praktizierte. 1944 für seine Leistungen im Zweiten Weltkrieg und 1963 zur Hundertjahrfeier seiner Gründung.

Im Henry-Dunant-Museum, das passenderweise im alten Spital Heiden besteht, wird vom 10.11.2019 bis zum 23.12.2020 eine «Kabinettausstellung» gezeigt mit dem zum Denken anregenden Titel: «Der Preis für den Frieden» - Alfred Nobels Auszeichnung von Henry Dunant bis Abiy Ahmed Ali.

Es lohnt sich, darüber nachzudenken, welchen Preis für den Frieden wir zahlen wollen bzw. dankbar dafür zu sein, dass wir in unseren Gegenden seit so langer Zeit doch im Frieden leben dürfen.

Die Namen Dunant und Nobel werden mit dem Bemühen um eine friedlichere Welt in Verbindung gebracht. Den Weg zum Frieden sehen die beiden schillernden Persönlichkeiten jedoch unterschiedlich. Während der Humanist Henry Dunant Regeln formuliert, welche die
Folgen von Kriegen abmildern sollen, hält der Chemiker Alfred Nobel die abschreckende Wirkung von Waffen für eine Möglichkeit, kriegerische Auseinandersetzungen zu verhindern. Der eine ist ein Mitgründer des Internationalen Roten Kreuzes, der andere erfindet das Dynamit. Die unterschiedlichen Lebenswege treffen sich am Ende: Alfred Nobel verfügt in seinem Testament die Vergabe von Preisen für besondere Leistungen in Physiologie oder Medizin, Literatur, Technik, Wirtschaft und, auf Anregung vont Bertha von Suttner, auch einen Preis für den Frieden. Träger des ersten Friedensnobelpreises 1901 ist eben Henry Dunant (er schrieb selber seinen Vornamen gelegentlich mit «i» oder mit "y»). Wie unterschiedlich die Vorstellungen von Friedensarbeit sein können und inwiefern die Konzeptionen

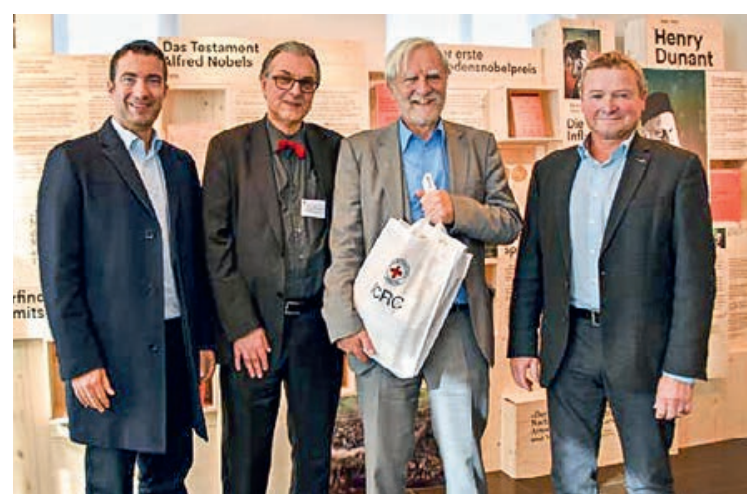

Andrea Caroni, Andreas Ennulat, Jürg Kesselring und Alfred Stricker in der Kabinettausstellung «Der Preis für den Frieden» im Henry-Dunant-Museum Heiden.

(Bild: IKS)

von Frieden dem jeweiligen Zeitgeist folgen, wird in der Ausstellung anhand von 33 ausgewählten Preisträgerinnen und Preisträgern deutlich. Aus Anlass der Vergabe des 100. Friedensnobelpreises im Jahr 2019 werden die Auszeichnung und die Vergabekriterien in der Ausstellung reflektiert. Diese bietet Gelegenheit, sich mit Friedenskonzepten, Friedensarbeit und mit dem eigenen Verständnis von (und dem eigenen Beitrag zu (?)) Frieden zu beschäftigen. Die Ausstellung ist auf $\mathrm{Holz}$ geprägt. Holztafeln dürfen gedreht werden, weil auf der Rückseite weitere Daten zu ausgezeichneten Organisationen und Personen stehen, beispielsweise über Bertha von Suttner, Martin Luther King oder Michail Gorbatschow. «Der Preis für den Frieden» informiert und fasziniert. Damit ist dem Henry-Dunant-Museum ein ganz spezielles Meisterstück gelungen. 